\title{
Selective COX-2 Inhibitor (Rofecoxib) Inhibits Vinorelbine Cytotoxicity in C6 Glioma Cells In Vitro
}

\author{
Sevilcan Tuna ${ }^{1}$, Meric A. Altinoz ${ }^{2}$, Aykut Karasu ${ }^{3}$, Ali Canbolat ${ }^{3}$ and Ayhan Bilir ${ }^{*}$ \\ ${ }^{I}$ Istanbul University, Istanbul Faculty of Medicine, Department of Histology and Embryology, Istanbul, Turkey \\ ${ }^{2}$ Halic University, Institute of Health, Medical Biology and Genetics, Istanbul, Turkey \\ ${ }^{3}$ Istanbul University, Istanbul Faculty of Medicine, Department of Neurosurgery, Istanbul, Turkey
}

\begin{abstract}
We examined the effects of gemcitabine, a novel nucleotide analogue, and vinorelbine, a semi-synthetic vinca alcaloid, in C6 glioma cell culture. We simultaneously monitored the modulation of its activity in combination with the telomerase inhibitory agent dimetilsülfoxid and with a specific cyclooxygenase- 2 inhibitory agent Rofecoxib. The effects of the gemcitabine/ vinorelbine combination were observed over a 96 hour period. Plating, S-phase (bromodeoxyuridinelabelling index) and ultrastructure were selected as the evaluation parameters of drug interactions.

Gemcitabine $(10 \mu \mathrm{g} / \mathrm{ml})$ was found to possess significant blocking activity of C6 glioma plating and cells' S-phase. Vinorelbine $(10 \mu \mathrm{g} / \mathrm{ml})$ also demonstrated significant inhibitory activity. Vinorelbine reduced BrdU-LI but was not as effective as gemcitabine. Rofecoxib $(10 \mu \mathrm{g} / \mathrm{ml})$ showed no synergism on cell inhibition either with gemcitabine or vinorelbine and protected against the S-phase depleting activity of vinorelbine.

Dimetilsülfoxid $(20 \mu \mathrm{g} / \mathrm{ml})$ reduced the effect of vinorelbine in spheroid culture. But at the final $96^{\text {th }}$ hour tie point dimetilsülfoxid reduced the increasing cell numbers which were previously seen in the gemcitabine group.

In conclusion, both gemcitabine and vinorelbine effectively reduced both the monolayer and spheroid growth of C6 glioma cells. At the single cell level, only dimetilsülfoxid could sensitise for gemcitabine but not vinorelbine. Despite reducing spheroid growth, treatment using cyclooxygenase-2 inhibitors with microtubule inhibitors should be avoided.
\end{abstract}

Keywords: C6 glioma, gemcitabine, vinorelbine, rofecoxib, DMSO.

\section{INTRODUCTION}

Glioblastoma multiforme (GBM) is the most common aggressive glioma resistant to therapeutic interventions, causing most patients to die within 1 year after diagnosis [1]. The success of treatment is hampered by factors such as the rapid growth, remarkable genetic and biological heterogeneity and high grade of these neoplasms [2]. C6 cells, derived from rat glial tumours induced by N-nitrosomethyl urea [3], are commonly used as an established cell line as a model to study glial cells. C6 glioma cells have been shown to be morphologically similar to GBM when injected into the brain of neonatal rats [4].

Gemcitabine (2,2-difluorodeoxycytidine $[\mathrm{dFdC}]$ ) is a deoxycytidine analogue that has demonstrated clinical activity in the treatment of solid tumours, including pancreatic and non-small cell lung cancer ([NSCLC]) $[5,6]$.

Vinorelbine is a semisynthetic vinca alcaloid that differs from the other drugs in the same family (such as vincristine and vinblastine), because of its relative specificity for mitotic tubules. The finding that it has fewer toxic effects on axonal microtubules leads to a reduction of vinorelbine-related neurotoxicity [7]. Gemcitabine and vinorelbine represent an

*Address correspondence to this author at the Istanbul University, Istanbul Faculty of Medicine, Department of Histology and Embryology, 34093, Çapa, İstanbul, Turkey; Tel: +9002124142000-32367;

Fax:+9002124142284; E-mail: bilira@istanbul.edu.tr attractive combination for clinical evaluation, because each is directed against a different cell target: the inhibition of DNA synthesis by gemcitabine, and selective activity against mitotic tubules in the case of vinorelbine [8]. The combination of gemcitabine and vinorelbine was well tolerated as a second-line regimen, with a low toxicity in NSCLC [9]. This combination is well tolerated especially in patients with advanced transitional cell carcinoma (TCC) who are unsuitable for cisplatin-based chemotherapy [10]. The effect of this combination in glioma is unknown. Based on this data, we investigated this combination in C6 glioma cell line.

Nonsteroidal anti-inflammatory drugs (NSAIDs) are the most commonly used drugs in inflammatory diseases, since they are effective in management of pain, fever, redness, oedema arising as a consequence of inflammatory mediator release [11]. Rofecoxib is a nonsteroidal anti-inflammatory agent that selectively inhibits cyclooxygenase-2 (COX-2), a critical enzyme in the conversion of arachidonic acid to prostaglandin $\mathrm{E} 2$. COX-2, the inducible isoform, is found in inflammatory and immune cells and is overexpressed in many malignant tumours [12]. COX-2 is up-regulated in the majority of high-grade gliomas indicating a potential role for COX-2 inhibitors as an adjuvant therapy for brain tumours [13]. According to these knowledgements we think to administer rofecoxib on brain tumours as an anti-inflammatory molecule which could limit the intra-cranial high blood pressure bound to the oedema. 
DMSO (dimetilsülfoxid) shows potent anti-tumour activity via the induction of differentiatin. During the induction of granulocytic differentiation in HL-60 promyelocytic leukaemia cells, it completely inhibits the expression of the M2 subunit of ribonucleotide reductase (RR) [14]. DMSO and antineoplastic agents exhibit synergistic cytotoxicity against human tumours in vitro. Combinations of DMSO and DHAD (mitoxantrone hydrochloride) produced 46-61\% increases above expected survival, demonstrating synergistic cytotoxicity in vivo that intraperitoneal (i.p.) injections of P388 leukaemia cells [15].

We raised the question if DMSO or rofecoxib could regress the growth of a malignant glial cell line and show a sensitization effect on vinorelbine and gemcitabine.

\section{MATERIAL AND METHODOLOGY}

\section{Cell Culture and Drugs}

C6 cells established from the American Type Culture Collection (ATCC) were maintained in Dulbecco's modified Eagle's Medium (DMEM, containing 100U/ml penicillin and $100 \mu \mathrm{g} / \mathrm{ml}$ streptomycin) (Biological Industries, Haemek, Israel) supplemented with $10 \%$ heat inactivated foetal bovine serum (FBS) (Biological Industries, Haemek, Israel). The flasks were kept in an incubator with a humidified atmosphere of $5 \% \mathrm{CO}_{2}$ at $37{ }^{\circ} \mathrm{C}$. Cells were transferred using $\mathrm{Ca}^{2+}$ and $\mathrm{Mg}^{2+}$ free Hanks' basic salt solution and $0.25 \%$ trypsin-tilendiamin tetraasetikasit (EDTA) (Biological Industries, Haemek, Israel). We used early passages $\left(4-7^{\text {th }}\right)$ of C6 cells after obtaining the cell line. Gemcitabine (Gemzar ${ }^{\circledR}$, Lilly), vinorelbine (Navelbine, Pierre Fabre Medicament), rofecoxib (Merck Sharp \& Dohme) and DMSO (D2650, Sigma) were dissolved in bidistilled water and added into cell culture in equal volumes.

\section{Plating Efficacy}

Cells prepared in $5 \mathrm{ml}$ of DMEM were plated into a sixwell plate in $1 \times 10^{5} / \mathrm{ml}$ concentration with $100 \%$ vitality. All drugs were added in equal volumes of $100 \mu 1$, and after 24 , 48, 72 and $96 \mathrm{~h}$, cells were harvested with trypsin-EDTA C (Biological Industries, Haemek, Israel).

\section{Spheroid Culture}

C6 cells were cultured at $37^{\circ} \mathrm{C}$ in a humidified atmosphere (5\% $\mathrm{CO}_{2}$ in air) in DMEM medium supplemented with $10 \%$ heat-inactivated FBS and antibiotics, and passed weekly. Spheroids were obtained by inoculating $10^{6}$ cells in $10 \mathrm{ml}$ of DMEM-FBS $10 \%$ in a petri dishes on a thin layer of agar $(10 \mathrm{ml}$ of a $0.75 \%(\mathrm{w} / \mathrm{v})$ solution of agar in DMEM-FBS $10 \%)$. Spheroids (approximately 2000-4000 cells per spheroid) were harvested by gentle repeated transfer, using a micropipette, of individual spheroids into the wells of a 24-well culture plate. Multicellular Tumour Spheroids (MTS) were then individually placed into the wells of a 24-well culture plate containing $1 \mathrm{ml}$ of DMEM-FBS $10 \%$ on a layer of $1 \mathrm{ml}$ of $0.75 \%(\mathrm{w} / \mathrm{v})$ agar in the same medium. Every 7 days $0.5 \mathrm{ml}$ of DMEM medium was gently removed from each well and the wells were then filled with the some amount of fresh medium.

\section{Bromodeoxyuridine-Labelling Index (BrdU-LI)}

BrdU (5-bromo-2-deoxyuridine ( $2 \mu \mathrm{M}, 1: 200$ dilution)) was added to the spheroids' medium with subsequent incu- bation for an additional $1 \mathrm{~h}$. Thereafter spheroids were gently removed from the surface of the solidified agar and washed in phosphate buffer saline (PBS, pH 7.4). Spheroids were fixed in $4 \%$ paraformaldehyde (Sigma Chemical Co., St. Louis, Missouri, USA) in PBS for $24 \mathrm{~h}$ at $4^{\circ} \mathrm{C}$ and then washed in phosphate-buffered saline (PBS). Following fixation the spheroids were dehydrated through graded ethanol, cleared in xylene, embedded in paraffin and $5 \mu \mathrm{m}$ coronal sections were cut on microtome (Leica MR 2145, Heerbrugg, Switzerland). Sections were dewaxed in xylene for 30 minutes. After soaking in a decreasing series of ethanol, sections were washed with distilled water and PBS for 10 minutes and then treated with $2 \%$ trypsin in $50 \mathrm{mM}$ Tris buffer ( $\mathrm{pH} \mathrm{7.5)}$ at $37^{\circ} \mathrm{C}$ for $15 \mathrm{~min}$ and washed with PBS. Sections were incubated in a solution of $3 \% \mathrm{H}_{2} \mathrm{O}_{2}$ for 15 minutes, then washed with PBS and incubated with primary mouse anti-BrdU antibody (1:250 dilution, LabVision, UK). Next the sections were incubated with biotinylated IgG followed by streptavidin- peroxidase conjugate (LabVision, UK). The sections were then washed and incubated with the AEC chromogen substrate system and counterstained with Mayer's haematoxylin. The immunostained slides were observed under light microscopy at magnifications of x 40 . BrdU-labelled cells were observed by the same person. BrdUpositive cell types were determined by observing dark red AEC nuclear staining. Unlabelled nuclei with only blue haematoxylin staining and pale brownish nuclei were considered to be negative. Ten adjacent sections and at last 3000 cells were evaluated for each group.

\section{Transmission Electron Microscopy}

The harvested spheroids were fixed with $2 \%$ glutaraldehyde in $0.1 \mathrm{~mol} / \mathrm{L}$ sodium cacodylate $(\mathrm{pH} 7.4)$ for 1 hour at $4{ }^{\circ} \mathrm{C}$. Samples were then washed twice for 10 minutes with sodium cacodylate with a $\mathrm{pH}$ value of 7.4 . They were then fixed with $2 \%$ osmium tetraoxide in $0.1 \mathrm{M}$ sodium cacodylate for 1 hour at room temperature. Samples were then washed 3 times for 5 minutes each with the same buffer. Cells were exposed to $1 \%$ uranyl acetate for 1 hour and washed again 3 times for 10 minutes each with the same buffer. Samples were dehydrated via a graded ethanol series. After embedding in Epon-812 (SPI Chem., Pensylvania, USA.), samples were sectioned to a thickness of 700 to $800 \mathrm{~A}^{\circ}$ on a Richert Ultramicrotom (OMS, Austria). Sections were post-stained with 5\% uranyl acetate for 30 minutes, followed by Reynolds lead citrate incubation. Samples were then examined with a Jeol 1011 transmission electron microscope.

\section{Statistical Analysis}

All data are expressed as the mean \pm SEM. Statistical analysis was performed by the 2-tailed Student t test. The accepted level of significance was set at $\mathrm{P}>0.05$.

\section{RESULTS}

\section{Plating Efficacy}

As shown in Fig. (1), cells in the control group exerted a increasing growth beginning with approximately 0.7 million cells at 24 hour, rising to 3.5 million cells at the 96 hour.

Gemcitabine at all times reduced the cell numbers, which occured with $82,8 \%$ inhibition at the 96 hour, and these reduction were statistically significant for 24, 48, 72 and 96 


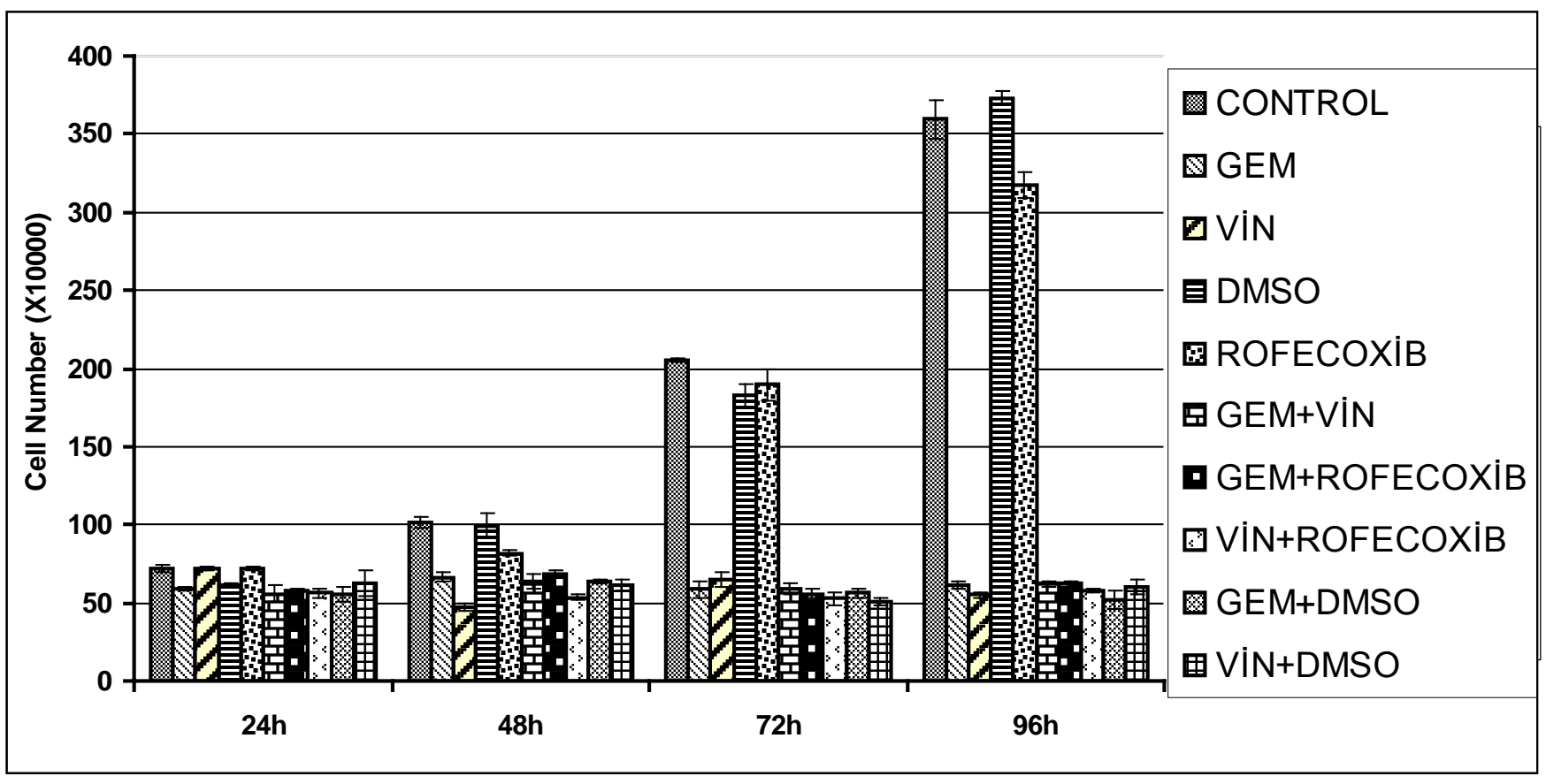

Fig. (1). Cell proliferation results of C6 cell line in monolayer at 24, 48, 72 and 96 hours. Control group exerted exponentially grown. Rofecoxib and DMSO exhibited comparable results to the control. Gemcitabine, vinorelbine and their combinations inhibited proliferation at all times.

hours time points with $\mathrm{p}<0.05, \mathrm{p}<0.01, \mathrm{p}<0.01$ and $\mathrm{p}<$ 0.01 , respectively. Vinorelbine reduced the cell numbers at all times, too. It occured with $84,72 \%$ inhibition at the 96 hours, in comparison to the control. $\mathrm{P}$ values were significant for 48, 72 and 96 hours $(\mathrm{p}<0.01)$. gemcitabine and vinorelbine combination reduced cell numbers, which occured at $82,73 \%$ inhibition at the 96 hour and with $\mathrm{p}<0.01, \mathrm{p}<0.01$, $\mathrm{p}<0.01$ for 48,72 and 96 hours, respectively. These results were similar to the inhibition of gemcitabine or vinorelbine alone and were not significant in comparison to gemcitabine alone or vinorelbine alone ( $\mathrm{p}>0.05$, Fig. 1).

Rofecoxib did not reduce cell number with $\mathrm{p}>0.05$ in comparison to control. The group with rofecoxib plus gemcitabine or vinorelbine significantly reduced the cell number in comparison to the control at all times ( $p>0.05$ in comparison to gemcitabine alone or vinorelbine alone (Fig. 1)).

DMSO reduced cell numbers with $14,67 \%$ inhibition at the 24 hour point which was statistically significant $(\mathrm{p}>$ $0.05)$. But at the other hours it was not reduced cell number and it was interestingly induced proliferation in comparison to control ( $p>0.05)$. When DMSO was combined with gemcitabine, growth inhibition reached to $85,51 \%$ at the 96 hours which were significant with $\mathrm{p}<0.05, \mathrm{p}<0.05, \mathrm{p}<0.01$ and $\mathrm{p}<0.01$ for $24,48,72$ and 96 hour time points, respectively. DMSO induced the inhibition of the proliferation effect of gemcitabine at all time points $(\mathrm{p}<0.01$, Fig. 1).

The DMSO and vinorelbine combination reduced cell numbers at 48 and 96 hour time points $(\mathrm{p}<0.01)$ in comparison to control. The inhibition rate was $40,92 \%$ and $83,21 \%$ for 48 and 96 hour time points, respectively. DMSO induced vinorelbine's inhibition effect at 24 and 72 hour time points with $\mathrm{p}<0.01$ in comparison to vinorelbine alone (Fig. 1).

\section{BrdU-Labelling Index (BrdU-LI)}

BrdU positive cells were observed in the periphery and also at the centre of the control spheroid sections (Fig. 2A). The labelling index of the control group was determined as $18,2 \%$ (Fig. 3). Gemcitabine reduced the labelling of spheroids as $1,3 \%$, which was statistically significant to the control $(\mathrm{p}<0.01)$ (Fig. 2B). The effect of vinorelbine was also statistically significant $(\mathrm{p}<0.01)$. Although vinorelbine decreased the labelling value of spheroids, this effect was heterogeneous because some spheroids exhibited high and some of them low staining (Fig. 2C). The average detected labelling index was $7,3 \%$. In the rofecoxib group, BrdU positive cells were observed at the periphery of the spheroids and the BrdU-LI was determined as $8,5 \%(\mathrm{p}<0.01)$. The labelling index of the DMSO group spheroids was $9,1 \%$ and this result was statistically significant compared to the control $(\mathrm{p}<0.01)$. The average labelling value determined was $1,9 \%$ in the gemcitabine plus vinorelbine group. This was statistically significant $(\mathrm{p}<0.01)$ when compared with the control and also with vinorelbine. So gemcitabine has a greater inhibitory effect than vinorelbine. The gemcitabine plus rofecoxib and the gemcitabine plus DMSO groups spheroids' labelling index significantly decreased to $1,5 \%$ and 
(A)

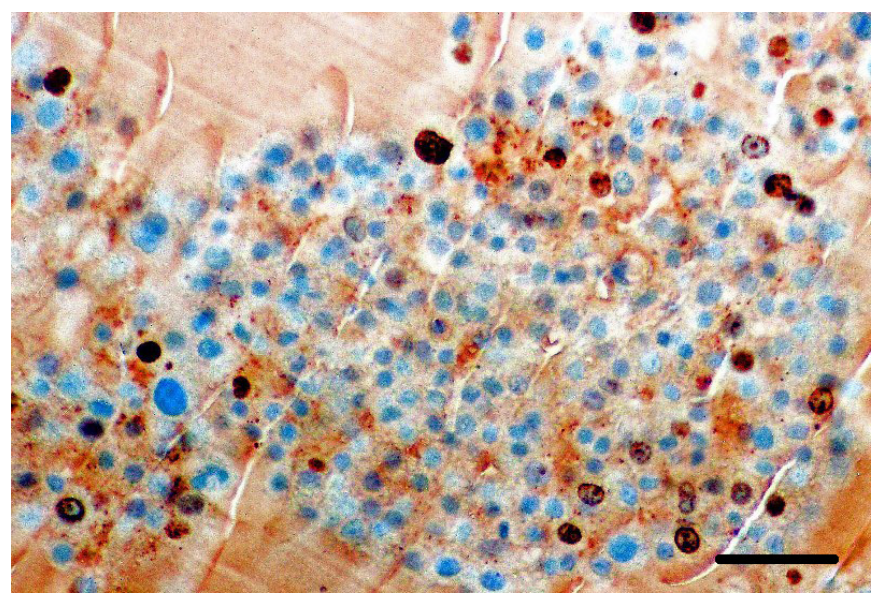

(C)

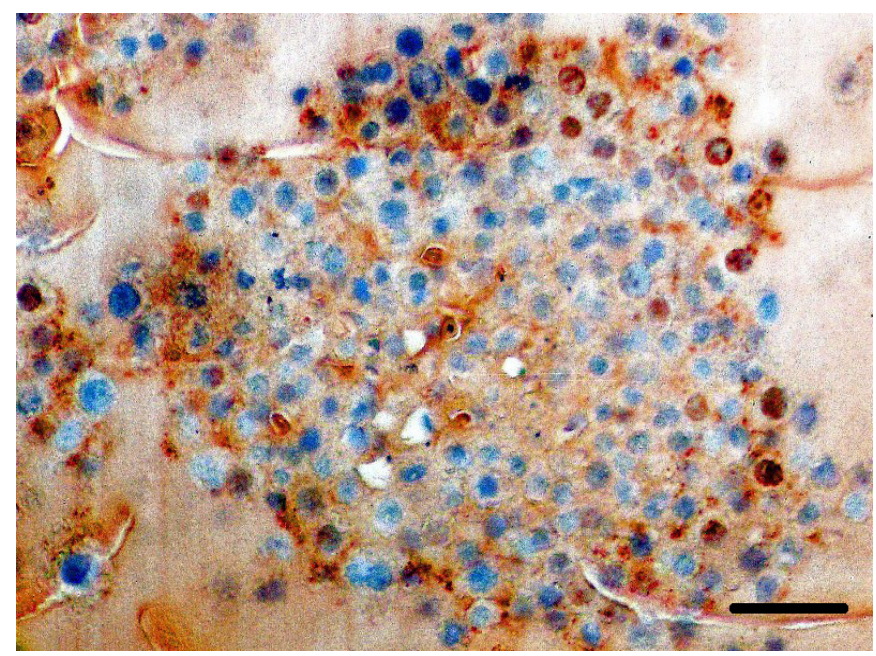

(B)

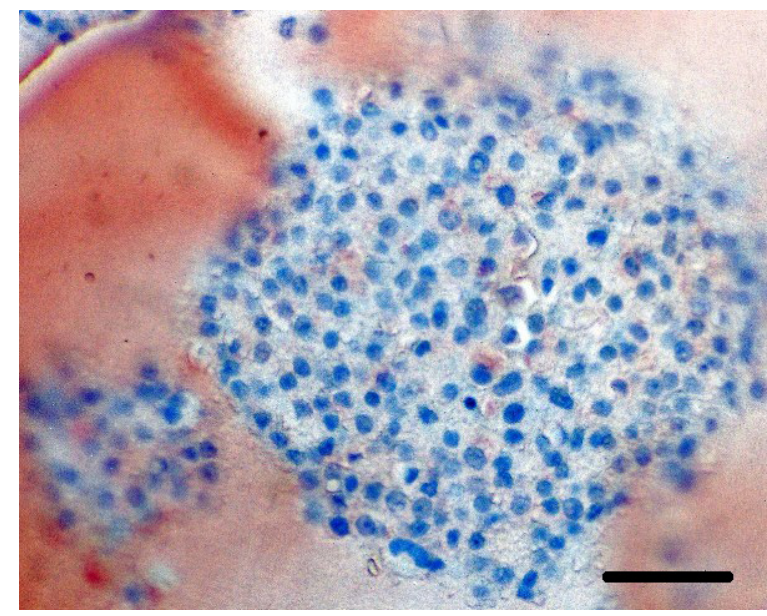

(D)

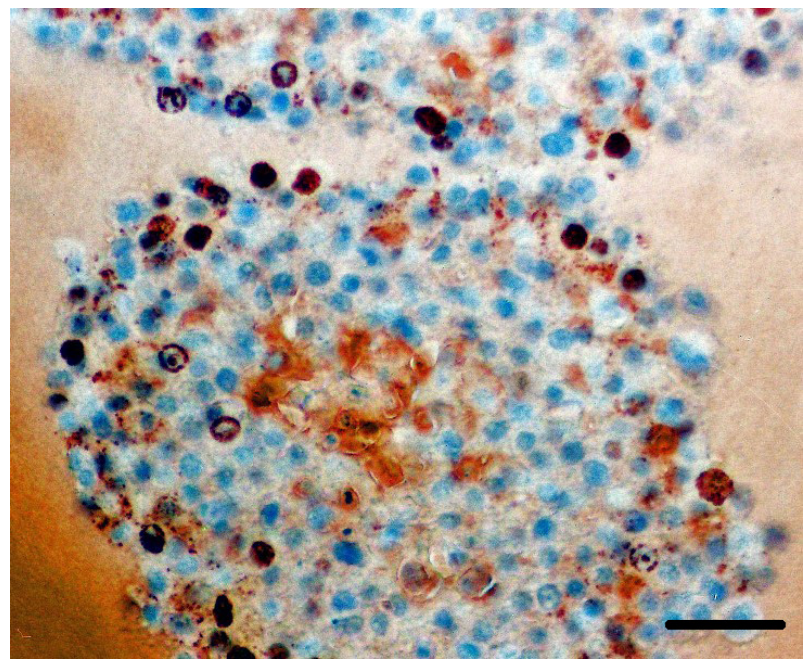

Fig. (2). Immunohistochemistry staining of C6 spheroid sections with BrdU antibody. (A) Control spheroid has stained cells in the centre of spheroid. Bar $25 \mu \mathrm{m}$ (B) gemcitabine spheroids showed very low staining. Bar $25 \mu \mathrm{m}$ (C) vinorelbine showed a greater labelling index than the gemcitabine group. Bar $25 \mu \mathrm{m}$ (D) The vinorelbine+rofecoxib group had more stained cells than vinorelbine or rofecoxib alone group. Bar $25 \mu \mathrm{m}$.

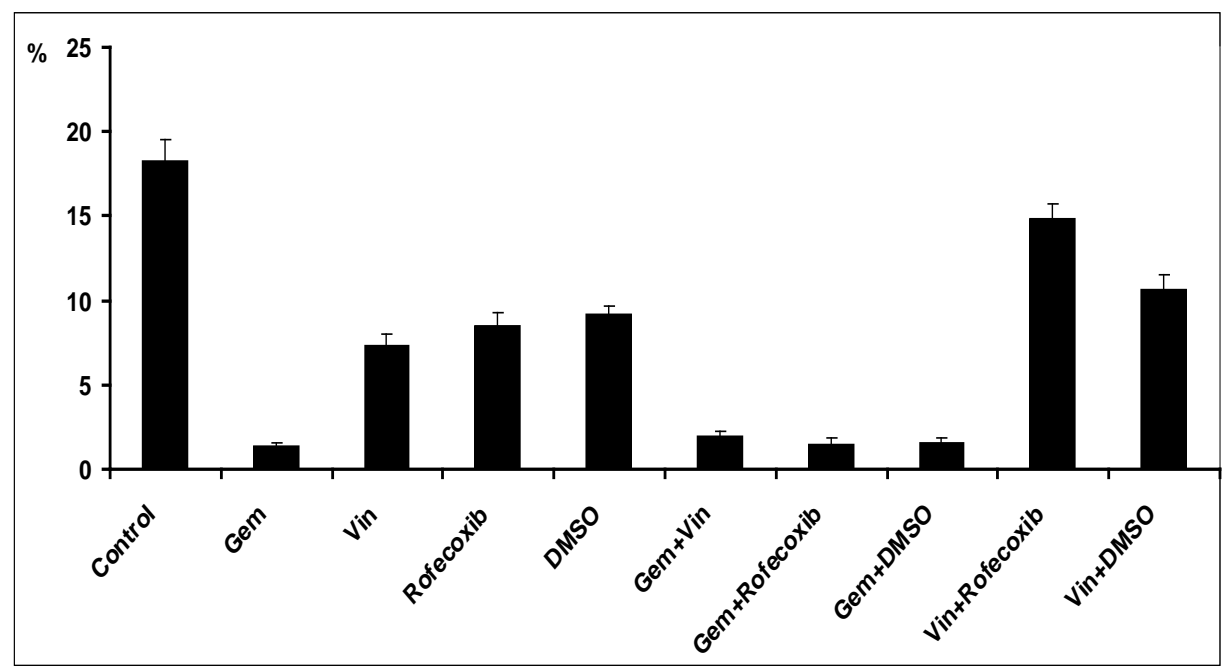

Fig. (3). BrdU labelling index of each group is spheroid at 48 hours. Immunohistochemistry was applied to spheroid sections given BrdU at 48 hours post drug administration. Interestingly the rofecoxib plus vinorelbine group staining was greater than vinorelbine or rofecoxib alone groups. 
$1,6 \%$, respectively $(\mathrm{p}<0.01)$. Again, gemcitabine had an inhibitory effect compared to rofecoxib and DMSO. The vinorelbine plus DMSO group spheroids' average labelling rate was $10,6 \%$, which was statistically significant compared to the control and vinorelbine groups. As a result, DMSO had a decreased labelling rate when combined with vinorelbine. The vinorelbine plus rofecoxib group spheroids' labelling rate was $14,8 \%$, which was statistically significant compared to the control $(p<0.01)$ (Fig. 2D). Rofecoxib decreased the inhibitory effect of vinorelbine.

\section{Transmission Electron Microscopy}

Cell membrane damage and cytoplasmic lysis was the definitive finding in gemcitabine, vinorelbine and gemcitabine plus vinorelbine groups' spheroids. As a result of weak intercellular connections the integrity of spheroid was destroyed. These findings were not consistent with the control group spheroids which had a heterochromatic nucleus, continuous membranes and smooth villus spreading out of the cell (Fig. 4A). DMSO exposed spheroids have normal integrity, but their vacuole number increased with lamellar intracytoplasmic bodies (Fig. 4B) and distinct nuclear invaginations. The DMSO plus vinorelbine group spheroids showed no alteration of cell ultrastructure. But the DMSO plus gemcitabine group spheroids had an increasing number of apoptotic cells especially in the centre of the spheroid.

The rofecoxib plus gemcitabine group spheroids had a vacuole in the cells and a blebbed cell membrane with apoptotic bodies in the intercellular area (Fig. 4C). Additionally, there were cells with a pykosis nucleus. In the rofecoxib alone group, cells showed no morphological changes but in the rofecoxib plus vinorelbine group (Fig. 4D), the rofecoxib inhibited vinorelbine's effect demonstrated by mitotic cells in this groups' spheroids.

\section{DISCUSSION}

The present study investigated the effects of gemcitabine, vinorelbine, rofecoxib and DMSO on the cell proliferation of the C6 cell line. A time dependent cell proliferation index, BrdU labelling index were employed alongside detection of ultrastructural changes by electron microscopy using three dimensional cell culture to evaluate these drugs. We demonstrated that gemcitabine and vinorelbine were very effective drugs on the C6 glioma cell line. Gemcitabine significantly reduced the cell numbers at all times and decreased the BrdU labelling index more than vinorelbine. This result was in agreement with the finding that this drug shows an effect on the S-phase [16].

In our study, when gemcitabine was combined with rofecoxib, inhibition of cell proliferation and reduction on the cell number in S-phase was demonstrated. But gemcitabine had a greater effect than rofecoxib. In combination with gemcitabine, NSAIDs have been shown to inhibit cell proliferation by the inhibition of cell cycle progression in human pancreatic cancer cell lines [17]. In contrast, we did not observe any synergistic inhibition of the C6 glioma cell line.

Studies have shown that DMSO is a telomerase inhibitor [18]. Shortening of telomere sites by pyrimidine analogues was proportional with tumour reply [19]. In our study, the combination of gemcitabine with DMSO, the DMSO induced a gemcitabine effect at the 96th hour time point in monolayer, but did not affect the BrdU-LI results. DMSO induced a gemcitabine effect in the monolayer, inhibiting DNA synthesis causing DNA damage and inhibiting telomerase. The second enzymatic target for DMSO is the reductase enzyme [14]. The inhibition of ribonucleotide reductase has been shown to have a very important role in the antitumoral activity of gemcitabine [20] and studies have shown that DMSO represses the M2 subunit of ribonucleotide reductase enzyme [21].

This study showed that cell proliferation was not inhibited at 24 hour by vinorelbine but was inhibited at later time points. Decreasing cell numbers were due to apoptotic cell death, supported by BrdU-LI, plating and electron microscopic results.

Vinorelbine interferes with tubulin depolimerization and inhibits mitotic spindle formation and so arrests cells at metaphase [22]. Interestingly, vinorelbine decreased the cell number at $48^{\text {th }}$ hours in monolayer but the cell number increased again at 72 hours. This situation means that vinorelbine resistant cells may proliferate after 48 hours. In this spheroid model, the cells were exposed to vinorelbine for 48 hour and then BrdU was incorporated. The BrdU-LI and cell proliferation results indicated an adjustment to each other.

Clinically, a gemcitabine and vinorelbine combination is tolerable in patients with NSCLC and the treatment results are constructive [23]. But in our study, in spite of the drugs having different targets in the cell, this combination showed similar results to the gemcitabine alone group.

The vinorelbine and rofecoxib combination results were similar to vinorelbine group results in monolayer. The BrdULI value of rofecoxib was interestingly and was shown to be higher in the sphreoid model compared to the vinorelbine alone and rofecoxib alone groups. This result is consistent with those reported previously with combination effects of paclitaxel and the Cox-2 inhibitor, NS-398, on epithelial ovarian cancer (EOC) cells however when aspirin was used instead of NS398, there was no change in result. The conclusion was that the combination of Cox-2 inhibitors and paclitaxel inhibited chemotherapy-induced apoptosis [24] which supports our result.

Joki et al. (2000) demonstrated that the Cox-2 inhibitor, NS-398, decreases tumour cell migration and proliferation of monolayer cell cultures and spheroid growth. Rofecoxib causes a change of expression of key genes related to cell cycle, angiogenesis, cell adhesion, apoptosis and cell proliferation in human pancreatic cancer and decelerates tumour growth in vivo [25]. In our study, the cell numbers in the rofecoxib group was approximate to the control group in monolayer culture. When rofecoxib was combined with gemcitabine, rofecoxib had no inductive effect on the inhibition of proliferation. Vinorelbine plus rofecoxib decreased cell numbers at 24, 48 and 96 hours but these results were similar to the vinorelbine alone group. According to the BrdU-LI results, rofecoxib decreased the labelling rate alone. 
(A)

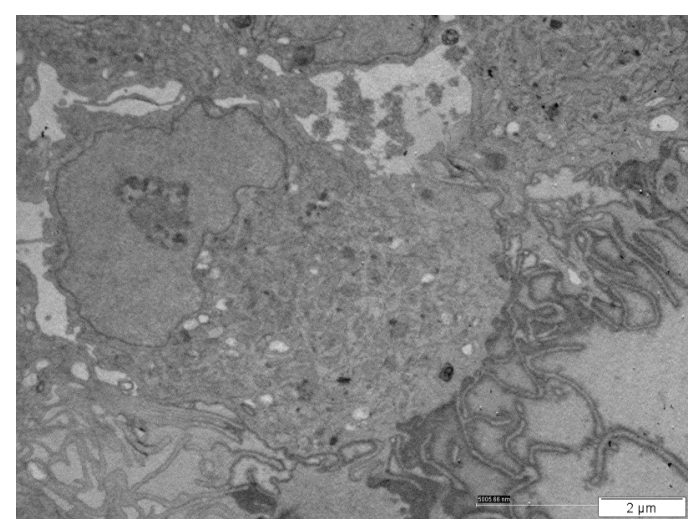

(B)

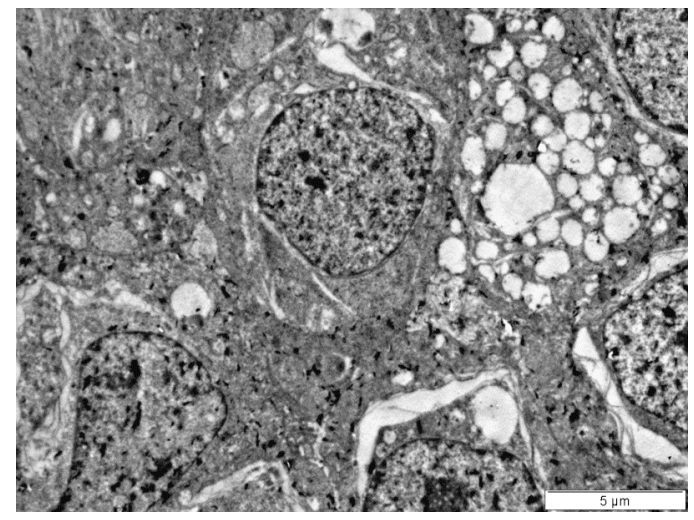

(C)

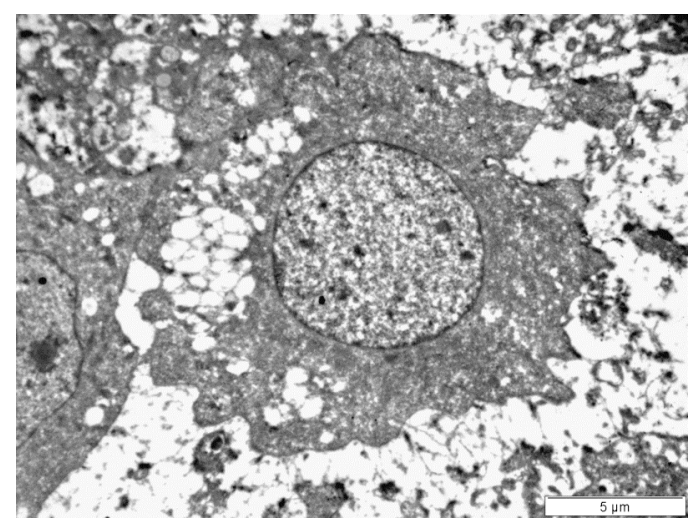

(D)

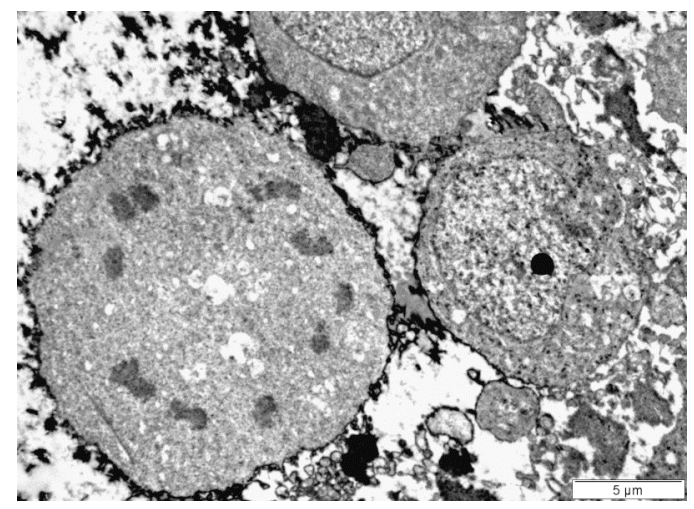

Fig. (4). Electronmicrographs of $\mathrm{C} 6$ glioma spheroids. (A) Control cells of spheroid had a smooth villus. (B) DMSO had more vacuoles than the other groups not in combination with DMSO. (C) Gemcitabine+rofecoxib group spheroids had intracellular apoptotic bodies. (D) Vinorelbine+rofecoxib group spheroids had mitotic cells. 
But when combined with vinorelbine inhibited the effect of vinorelbine and showed high BrdU-LI degree according to administrations of drugs alone. Rofecoxib can be used on brain tumours as an anti-inflammatory molecule which could limit the intra-cranial high blood pressure bound to the oedema. But according to our results these drugs should not use together.

The vinorelbine and DMSO combination decreased cell numbers at 24 and 72 hours in monolayer and the BrdU-LI result was higher than the vinorelbine alone group. Electron microscopy was used to investigate if DMSO protected cells in the spheroid model at 48 hour. According to electron microscopy observations, the DMSO plus vinorelbine group spheroids showed no alteration of cell ultrastructure. But the DMSO plus gemcitabine group spheroids had an increasing number of apoptotic cells especially in the centre of the spheroid.

\section{CONCLUSION}

Both gemcitabine and vinorelbine were found to be effective in reducing both the monolayer and spheroid growth of C6 glioma cells. When considering single cell behaviour, DMSO could sensitize for gemcitabine but not vinorelbine. Despite reducing spheroid growth, COX-2 inhibitors should be avoided for treatment in combination with microtubule inhibitors.

\section{ACKNOWLEDGEMENT}

This work was supported by Research Fund of the Istanbul University. Project number: T-541/21102004.

\section{ABBREVIATIONS}

$$
\begin{array}{ll}
\text { GBM } & =\text { Glioblastoma multiforme } \\
\text { dFdC } & =\text { 2,2-difluorodeoxycytidine } \\
\text { NSCLC } & =\text { Non-small cell lung cancer } \\
\text { TCC } & =\text { Transitional cell carcinoma } \\
\text { COX-2 } & =\text { Cyclooxygenase-2 } \\
\text { DMSO } & =\text { Dimetilsülfoxid } \\
\text { ATCC } & =\text { American type culture collection } \\
\text { DMEM } & =\text { Dulbecco's modified Eagle's Medium } \\
\text { FBS } & =\text { Fetal bovine serum } \\
\text { EDTA } & =\text { Etilendiamin tetraasetikasit } \\
\text { MTS } & =\text { Multicellular tumour spheroids } \\
\text { BrdU-LI } & =\text { Bromodeoxyuridine-labelling index } \\
\text { BrdU } & =\text { Bromodeoxyuridine (5-bromo-2- } \\
\text { PBS } & =\text { deoxyuridine) } \\
\text { NSAID } & =\text { Nonosphate-buffered saline } \\
\end{array}
$$

\section{REFERENCES}

[1] Grobben B, Deyn PP, Slegers H. Rat C6 glioma as experimental model system for the study of glioblastoma growth and invasion. Cell Tissue Res 2002; 310: 257-70.
[2] Lyden DC, Mason WP, Finlay JL. The expanding role of chemotherapy for pediatric supratentorial malignant gliomas. J NeuroOncol 1996; 28: 185-91.

[3] Benda P, Lightbody J, Sato G, Levine L, Sweet W. Differentiated rat glial strain in tissue culture. Science 1968; 161: 370-1.

[4] Auer R, Del Maestro RF, Anderson R. A simple and reproducible experimental in vivo glioma model. Can J Neurol Sci 1981; 8: 32531.

[5] Fossella FV, Lippman SC, Shin DM, et al. Maximum-tolerated dose defined for single-agent gemcitabine: a Phase I doseescalation study in chemotherapy-naive patients with advanced non-small-cell lung cancer. J Clin Oncol 1997; 15: 310-16.

[6] Storniolo AM, Enas AH, Brown CA, Thenberg ML, Hilsky R. An investigational new drug treatment program for patients with gemcitabine-results for over 3000 patients with pancreatic carcinoma. Cancer (Phila) 1999; 85: 1261-68.

[7] Binet S, Fellous A, Lataste H, Krikorian A, Couzinier JP, Meininger V. In situ analysis of the action of navalbine on various types of microtubules using immunofluorescence. Semin Oncol 1989; 16: $5-8$.

[8] Lilenbaum R, Cano R, Schwartz M, et al. Gemcitabine and vinorelbine in advanced nonsmall cell lung carcinoma a phase II study. Cancer 2000; 88: 557-62.

[9] Hainsworth JD, Burris HA $3^{\text {rd }}$, Erland JB, et al. Minnie Pearl Cancer Research Network. Combination chemotherapy with gemcitabine and vinorelbine in the treatment of patients with relapsed or refractory small cell lung cancer: phase II trial of the Minnie Pearl Cancer Research Network. Cancer Invest 2003; 21: 193-9.

[10] Turkolmez K, Beduk Y, Baltaci S, Gogus C, Gogus O. Gemcitabine plus vinorelbine chemotherapy in patients with advanced bladder carcinoma who are medically unsuitable for or who have failed cisplatin-based chemotherapy. Eur Urol 2003; 44: 682-6.

[11] Mitchell JA, Warner TD. Cyclooxygenase-2: pharmacology, physiology, biochemistry and relevance to NSAID therapy. Br J Pharmacol 1999; 128: 1121-32.

[12] Oshima M, Murai N, Kargman S, et al. Chemoprevention of intestinal polyposis in the Apcdelta716 mouse by rofecoxib, a specific cyclooxygenase-2 inhibitor. Cancer Res 2001; 61: 1733-40.

[13] Joki T, Heese O, Nikas DC, et al. Expression of cyclooxygenase 2 (COX-2) in human glioma and in vitro inhibition by a specific COX-2 inhibitor, NS-398. Cancer Res 2000; 60: 4926-31.

[14] Chen Y, Sokoloski JA, Chu E, Sartorelli AC. Regulation of the expression of enzymes involved in the replication of DNA in chemically-induced granulocytic differentiation of HL-60 leukemia cells. Leuk Res 1998; 22: 687-95.

[15] Pommier RF, Woltering EA, Milo G, Fletcher WS. Synergistic cytotoxicity of combinations of dimethyl sulfoxide and antineoplastic agents against P388 leukemia in CD-F1 mice. Anticancer Drugs 1992; 3(6): 635-9.

[16] Cappella P, Tomasoni D, Faretta M, et al. Cell cycle effects of gemcitabine. Int J Cancer 2001; 93(3): 401-8.

[17] Yip-Schneider MT, Sweeney CJ, Jung SH, Crowell PL, Marshall MS. Cell cycle effects of non-steroidal anti-inflammatory drugs and enhanced growth inhibition in combination with gemcitabine in pancreatic carcinoma cells. J Pharmacol Exp Ther 2001; 298: 97685 .

[18] Sharma S, Raymond E, Soda H, et al. Dimethyl sulfoxide (DMSO) causes a reversible inhibition of telomerase activity in a Burkitt lymphoma cell line. Leuk Res 1998; 22: 663-70.

[19] Terashima M, Takiyama I, Vesugi N, et al. Telomerase assay as a possible predictor of the response to anticancer chemotherapy. Anticancer Res 2000; 20: 293-7.

[20] Johnson SA. Clinical pharmacokinetics of nucleoside analogues: focus on haematological malignancies. Clin Pharmacokinet 2000; 39: 5-26.

[21] Boulares AH, Giardina C, Inan MS, Khairallah EA, Cohen SD Acetaminophen inhibits NF-kappa B activation by interfering with the oxidant signal in murine Hepa 1-6 cells. Toxicol Sci 2000; 55: 370-5.

[22] Hanley ML, Elion GB, Colvin OM, et al. Therapeutic efficacy of vinorelbine against pediatric and adult central nervous system tumours. Cancer Chemother Pharmacol 1998; 42: 479-82. 
[23] Baron F, Cueva J, Grana B, et al. Gemcitabine plus vinorelbine for the treatment of advanced non-small cell lung cancer. Eur J Cancer 2001; 37: 1381-4.

[24] Munkarah AR, Genhai Z, Morris R, et al. Inhibition of paclitaxelinduced apoptosis by the specific COX-2 inhibitor, NS398, in epithelial ovarian cancer cells. Gynecol Oncol 2003; 88: 429-33.
[25] Tseng WW, Deganutti A, Chen MN, Saxton RE, Liu CD. Selective cyclooxygenase-2 inhibitor rofecoxib (Vioxx) induces expression of cell cycle arrest genes and slows tumor growth in human pancreatic cancer. J Gastrointest Surg 2002; 6: 838-43.

(C) Tuna et al.; Licensee Bentham Open.

This is an open access article licensed under the terms of the Creative Commons Attribution Non-Commercial License (http: //creativecommons.org/licenses/by-nc/ $3.0 /$ ) which permits unrestricted, non-commercial use, distribution and reproduction in any medium, provided the work is properly cited. 